\title{
El cine regional en el Perú
}

\author{
Emilio Bustamante y Jaime Luna Victoria \\ (Universidad de Lima)
}

Recibido: 16/6/2014

Aprobado: 20/7/2014

\begin{abstract}
Resumen: Se expone un panorama del llamado cine regional en el Perú. Se señalan las causas de su aparición; se describe el perfil del cineasta regional; se explica el sistema de producción, realización, distribución y exhibición de las películas regionales; se analizan los principales géneros abordados por los cineastas regionales, y se mencionan algunas de las películas más importantes de cada género, así como los modos narrativos, la dramaturgia y el lenguaje audiovisual empleado en los filmes. Por último, se reseña el apoyo institucional brindado al cine regional, en especial de parte de Estado a través de los concursos convocados primero por Conacine y después por el Ministerio de Cultura.
\end{abstract}

Palabras clave: cine / cine peruano / cine regional / regiones

\section{Regional Cinema in Peru}

Summary: This article exposes an overview of the so called 'regional cinema' in Peru. The article describes the causes of their appearance, the profiles of regional directors, the production system, fulfillment, distribution and exhibition of regional films, it is analyzed the main genres addressed by regional filmmakers and some of the most important films in every genre, the narrative models, the drama and visual language are mentioned as well. Finally, it mentions the institutional support given to regional cinema, especially from the State through competitions held by CONACINE and the Ministry of Culture of Peru.

Key words: cinema / Peruvian cinema / regional cinema / regions 


\section{Introducción}

$\mathrm{D}$ esde 1996 (año en que se realizó la película ayacuchana Lágrimas de fuego) a la fecha, se ha desarrollado de manera continua en el Perú un cine hecho fuera de Lima que cuenta ya con alrededor de ciento cincuenta largometrajes, la mayoría de los cuales se ha exhibido comercialmente en su lugar de origen y sitios aledaños.

Hay más de sesenta realizadores repartidos en dieciséis regiones que han dirigido por lo menos un largometraje. Las regiones de mayor actividad cinematográfica son Ayacucho y Puno, seguidas por Junín y Cajamarca. También se han hecho largometrajes en Arequipa, Apurímac, Cusco, Loreto, La Libertad, Lambayeque, Piura, Tacna, Huancavelica, Huánuco, Pasco y San Martín. En Arequipa, Cusco y Lambayeque hay una considerable producción de cortos y mediometrajes realizados, principalmente, por jóvenes estudiantes o recién egresados de las facultades de Comunicación.

A pesar de su evidente importancia, el llamado cine regional es casi invisible en Lima. A esto ha contribuido, sin duda, su escasa exhibición en el circuito comercial de los multicines (en diez años, solo siete largometrajes han sido estrenados allí), pero también la poca atención que le han brindado los medios de comunicación, la crítica especializada, sus colegas cineastas de Lima, los centros académicos y las entidades del Estado.
El presente artículo es un avance de la investigación que los autores venimos realizando para el Instituto de Investigación Científica de la Universidad de Lima, y tiene como base las entrevistas a profundidad realizadas a ochenta y un directores de cine regional de largos y cortometrajes.

\section{Causas de su aparición}

La aparición simultánea de cineastas en distintas partes del país es producto de la convergencia de un factor tecnológico y un componente cultural. Por un lado, el vertiginoso desarrollo de la tecnología, que ha tenido como resultado el abaratamiento de los equipos de grabación en video (primero, analógicos y, luego, digitales) y de las computadoras personales, ha generado un boom de producción cinematográfica independiente a nivel global. Por el otro, culturas tradicionalmente orales y no escritas, como la andina y la amazónica, parecen haber encontrado en el lenguaje audiovisual un vehículo expresivo ideal. No es casual que los principales centros de producción cinematográfica regional se ubiquen en la zona andina de nuestro país.

\section{Perfil del cineasta regional}

La mayoría de los cineastas regionales son de extracción popular y han aprendido a hacer cine en la práctica, de manera empírica o autodidacta. Su formación audiovisual no es pues, aca- 
démica, aunque suelen tener estudios técnicos o superiores en otras áreas como educación, derecho o ciencias sociales. Muchos han comenzado como actores, al estilo de cineastas célebres como Charles Chaplin, Buster Keaton, John Ford, Orson Welles, Ingmar Bergman o Elia Kazan.

Los pocos que han recibido cierta formación universitaria en al área audiovisual pertenecen a familias más acomodadas o son parte de la generación más joven, que ha podido acceder a alguna de las facultades de Comunicación.

Entre las excepciones destaca el caso de Miguel Barreda, arequipeño que luego de terminar el colegio viajó a Alemania, donde estudió Literatura y Cine. En su estadía de casi veinte años en Europa, Barreda dirigió varios cortos y algunos mediometrajes. Vino al Perú para dirigir $Y$ si te vi, no me acuerdo (2000), su primer largometraje. Poco después regresó a vivir a Arequipa, donde ha realizado varios documentales institucionales antes de los largos de ficción Ana de los Ángeles (2012) y Encadenados. Todavía por estrenarse, Encadenados ganó el Concurso de Proyectos de Largometraje Exclusivo para las Regiones del Ministerio de Cultura en el año 2012.

Otro caso especial es el de Óscar Liza, hijo de peruano y argentina que estudió Administración de Negocios y se dedica al marketing y otras actividades comerciales. Vive en Chiclayo desde hace quince años y recientemente se interesó en la música, formó un estudio de grabación para producir sus propias creaciones, luego empezó a hacer videoclips y, finalmente, decidió realizar una película que se convirtió en Trampas de tu lado oscuro (2013), largometraje estrenado comercialmente en un multicine de Chiclayo y otro de Lima.

Entre los más jóvenes puede mencionarse a Omar Forero, de la ciudad de Trujillo, que egresó de la Facultad de Ciencias de la Comunicación de la Universidad Privada Antenor Orrego. Dirigió algunos cortometrajes y vivió dos años en Estados Unidos, donde cursó algunos talleres de cine. Ha realizado tres largometrajes: Los actores (2006), El ordenador (2012) y Chicama (2012). Con el proyecto de este último ganó el Concurso Exclusivo para las Regiones del Conacine en 2010.

En Iquitos está Dorian FernándezMoris, joven publicista hijo de un empresario cubano y de una dama loretana, que incursionó en la realización audiovisual con el cortometraje $\mathrm{Chu}$ llachaqui (2008), el cual, a pesar de durar solo media hora, se estrenó comercialmente en un multicine de Iquitos con gran éxito de público. Luego del cortometraje Inmortal (2008) y el mediometraje El último piso (2009), Dorian Fernández-Moris realizó con sus propios recursos el largometraje Cementerio general (2013), que se estrenó en el circuito de multicines a nivel nacional. Tuvo más de setecientos mil espectadores, con lo que se ha convertido en 
una de las películas más taquilleras de la historia del cine peruano.

Mención aparte merece el hecho de que casi todos los cineastas regionales que han llegado a dirigir un largometraje son de sexo masculino. En años más recientes, sin embargo, han aparecido algunas realizadoras de cortos y mediometrajes que, en todos los casos, son egresadas universitarias de clase media.

La arequipeña Cecilia Cerdeña, por ejemplo, estudió Psicología y ha realizado varios cortos experimentales y el mediometraje Metanoia (2013). La también arequipeña Karina Cáceres estudió publicidad y luego dirección de cine en la Escuela Internacional de Cine y Televisión en Cuba. Ha dirigido algunos cortos y el mediometraje Cable a tierra (2013). Cabe mencionar también a la cajamarquina Luz Isabel Guarniz, quien ha sido productora de tres documentales, y a la huancaína Nina Peñaloza, productora y actriz de algunos largos de ficción (en uno de los cuales es también guionista).

Dos casos especiales son los de Jaqueline Riveros de Huancayo y Gisella Burga de Chiclayo. La primera solo había dirigido un cortometraje durante sus estudios de Ciencias de la Comunicación en la Universidad del Centro, cuando ganó en 2011 uno de los Concursos de Proyectos de Largometraje Exclusivo para las Regiones del Conacine con Yawar Wanka, película que está terminando de realizar. La segunda emigró de niña a España, donde estu- dió Comunicaciones en la Universidad Complutense de Madrid. Al volver al Perú hace unos años, ha dirigido, además de algunos cortos, el mediometraje documental Yuraktukto (2013).

\section{Producción y realización}

En su mayoría, los cineastas regionales son, por necesidad, pequeños empresarios que invierten su propio dinero en la producción de una película. Trabajan muchas veces con su familia o amigos, y hacen casi siempre el triple rol de directores, productores y guionistas, si no son también actores y camarógrafos. Los auspicios o "canjes" publicitarios de empresas privadas son pocos y la contribución económica del Estado es inexistente, salvo escasísimas excepciones. Los gobiernos locales (regional o municipal) no suelen considerar el cine una actividad cultural o artística y, por lo tanto, no están dispuestos a entregar recursos a los realizadores.

Estas condiciones informales de trabajo tienen consecuencias laborales, comerciales y artísticas que influyen en el resultado final.

Los actores y los técnicos que participan en la producción de una película regional, generalmente, no reciben retribución económica; en el mejor de los casos, se les paga una cantidad "simbólica", con cargo a que esta se incremente luego del estreno del filme y de acuerdo con las ganancias que se 
generen. Los acuerdos son verbales y han tenido, no pocas veces, como consecuencia conflictos de todo calibre, desde rompimientos amicales hasta procesos judiciales que han llegado a durar, incluso, años.

Las querellas por la autoría y/o la propiedad de una película también se han producido con relativa frecuencia. El resultado, en algunos casos, ha sido que existan versiones diferentes de una misma película como sucede con la ayacuchana Lágrimas de fuego (1996), de la que José Huertas y Luis Berrocal tienen una versión y Mélinton Eusebio otra. El primer intento de Héctor Marreros de hacer una película sobre el santo popular cajamarquino Udilberto Vásquez es otro ejemplo. Al no ponerse de acuerdo con sus socios César Bueno y Lizardo Huamán, estos se quedaron con las cintas de toda la grabación y editaron la película Inocencia infinita. Por su parte, Marreros volvió a filmar su guion y el resultado es su ópera prima Justicia santa (2003). Unos años después hizo un remake titulado Milagroso Udilberto Vásquez (2006). Recientemente, el cineasta de Quinua, Julio Oré, y sus socios ayacuchanos Jorge Gaitán y David Acosta se han disputado la propiedad de la película Marimacha: La Encarnación (2013).

La urgencia de recuperar la inversión obliga a los cineastas de Ayacucho, Puno, Junín y Cajamarca a saltarse el paso de la producción de cortometrajes, que normalmente sirve para ensayar la técnica y aprender el lenguaje cinematográfico. Otro tanto sucede con el género documental, que la mayoría no practica porque no les da réditos.

Una estrategia de financiamiento parcial, que está bastante extendida, consiste en convocar a castings que son, a la vez, talleres de actuación. Debido a que en provincias hay escasez de intérpretes, estas convocatorias suelen tener bastante éxito y utilizan el atractivo de que los mejores alumnos participarán, finalmente, en la realización de una película. De esta manera, terminan siendo una significativa fuente de ingresos para la producción del filme.

En la mayoría de los casos, los cineastas regionales no escriben un guion literario con todos y cada uno de los diálogos y las escenas de la película por realizar. Generalmente, tienen como guía un argumento de unas cuantas páginas, junto a esbozos de diálogos y situaciones principales. A pesar de que esta práctica está empezando a cambiar en los últimos años debido, entre otras causas, al aprendizaje autodidacta de los formatos y técnicas del guion que realizan los cineastas a través de internet, todavía muchos debutantes no escriben un guion literario. Sin duda, la oralidad ancestral está detrás de ello, aunque hay motivos más pragmáticos e inmediatos, como el hecho de que los directores se cuidan mucho de que otros cineastas de la región les plagien el proyecto y se adelanten a ellos en la realización y estreno de la cinta. Demás está decir que 
son menos, aun, los que preparan un guion técnico.

Los rodajes de las películas regionales se extienden normalmente a lo largo de meses e, incluso, años. Se filma cada vez que se reúne el dinero suficiente $y$, por lo tanto, el rodaje es esporádico. Una consecuencia negativa de esta forma de trabajo es que los actores suelen abandonar el proyecto por cansancio o debido a que dejan la localidad por razones laborales, económicas o de estudios. Varias películas se han visto afectadas por esto. En algunos casos, los cineastas han tenido que volver a filmar todas las escenas de un personaje con otro intérprete. En otros, han rehecho el guion hasta donde se ha podido para disimular la súbita desaparición de un personaje. No es raro encontrar incoherencias narrativas a causa de estas deserciones actorales. El abandono de los técnicos también suele traer consecuencias en el resultado final de una cinta, generalmente, porque el camarógrafo es también el dueño de la cámara. Por lo tanto, algunas películas han sido filmadas con cámaras distintas y la diferencia en la calidad del registro se hace evidente.

Se utilizan diversas estrategias para ahorrar gastos de producción. Por ejemplo, se prefieren, en la medida de lo posible, las escenas diurnas para evitar las complicaciones y costos de la iluminación artificial. Las locaciones se reducen al mínimo posible y muchas veces se filma directamente en la calle con el público real. Cuando se necesita una locación especial, se trata de conseguirla prestada (la casa particular de un amigo o un local del Estado) o como canje (en un restaurante o un ómnibus, por ejemplo). En otros casos, se opta por el rodaje en las afueras de la ciudad o en pueblos cercanos. La posproducción se realiza normalmente en computadoras domésticas, utilizando programas de edición piratas o bajados gratuitamente de internet.

El rango de costos de las producciones regionales es muy amplio: de algunos cientos de soles a decenas de miles. En general, por la manera informal de trabajar, los propios cineastas tienen dificultades a la hora de calcular cuánto han gastado en una película. El transporte y la alimentación pueden ser los gastos principales, ya que, como hemos señalado, los actores y los técnicos no cobran, las cámaras se consiguen prestadas, se usa el micrófono incorporado de la cámara, la dirección artística es franciscana, en muchos casos los actores utilizan su propia ropa, etc.

\section{Exhibición y distribución}

Para exhibir sus películas, los cineastas regionales han utilizado las salas de cine tradicionales que todavía existen en las ciudades de provincias. Algunas de ellas se encontraban en desuso y han sido reabiertas por gestión de los realizadores, quienes llevan consigo e instalan equipos multime- 
dia de proyección, sistemas de sonido e incluso pantallas improvisadas. De no contar con estas salas, que suelen tener mucha mayor capacidad que las de los actuales multicines, los cineastas regionales recurren a teatros municipales, coliseos, colegios, auditorios particulares e incluso a la proyección al aire libre.

Ayacucho y Puno son las regiones que lideran la explotación comercial de películas regionales. La exhibición se realiza primero en las ciudades principales y luego en las más pequeñas, hasta llegar a pueblos y caseríos. El área de distribución se amplía luego a las regiones vecinas e incluso a las más lejanas, aunque esto ya depende del empeño de cada cineasta que tiene que viajar personalmente con la matriz de su película para evitar la piratería.

En Junín y Cajamarca la explotación comercial es bastante más restringida. Se limita a la ciudad de origen y, en la mayoría de los casos, con pocas funciones por película. La excepción en Junín es Daniel Núñez, pues el gran éxito comercial de su película Sufrimiento de madre (2009) lo impulsó a hacer un amplio recorrido por distintas regiones. Sin embargo, no fue él quien capitalizó el éxito de su cinta, sino la iglesia evangélica que auspició la producción. Héctor Marreros, en Cajamarca, tuvo buena taquilla con algunas de sus primeras películas hasta la exhibición de Milagroso Udilberto Vásquez, pero luego, ante la llegada de los multicines, ha optado por ceder sus siguientes producciones a un canal de cable que le facilita los equipos de filmación a cambio de la exclusividad de la emisión.

En Arequipa, Cusco, Lambayeque, La Libertad y Loreto, salvo las excepciones de Ana de los Ángeles, Trampas de tu lado oscuro, Chullachaqui, Cementerio general y Chicama ya mencionadas, la exhibición es en centros culturales y cineclubes, donde usualmente el público no paga entrada o el boleto tiene un costo mínimo.

\section{Géneros}

La mayoría de las películas son de ficción; pero también se han realizado documentales, experimentales y de animación. Dentro de la ficción los géneros más abordados son el fantástico (especialmente en su variante del horror), el melodrama y el realismo social. También se han realizado comedias, policiales, filmes de artes marciales y de temática religiosa. En algunos casos, encontramos mezcla de géneros. En todos, aparece la violencia como un elemento destacado.

\section{Fantástico}

Ayacucho es la región donde se ha producido la mayor cantidad de películas de género fantástico. La mayoría de ellas se ubican dentro del subgénero del horror, y tienen como personajes habituales a seres míticos regionales. Los personajes más frecuentes en 
los filmes ayacuchanos son jarjachas, pishtacos y condenados. Los dos últimos (pishtacos y condenados) aparecen también en películas de otras regiones (Puno y Junín). En las películas ayacuchanas encontramos además a la uma (o cabeza voladora de bruja) y el Aya Tullu. En una película puneña aparece el Kharisiri. También se encuentran filmes con seres fantásticos amazónicos (el Tunche y el Chullachaqui) y provenientes de leyendas urbanas (María Marimacha y el fantasma arequipeño Mónica).

El jarjacha (qarqacha, qarqaria o jarjaria) es un monstruo andino que toma la forma de un animal (generalmente, una llama), emite un sonido característico (jar-jar-jar o qar-qar-qar), ronda de noche, inmoviliza a sus víctimas (con un escupitajo) y les devora el cerebro. El jarjacha es, durante el día, un ser incestuoso que habita dentro de la comunidad. Aparece en filmes como Qarqacha, el demonio del incesto (2002) de Mélinton Eusebio, Incesto en los Andes: la maldición de los jarjachas (2002) y La maldición de los jarjachas 2 (2003) de Palito Ortega Matute, Sin sentimiento (2007) de Jesús Contreras Matías, Jarjacha 3 (2012) de Palito Ortega Matute, y Jarjacha vs. Pishtaco: la batalla final (2011) de Nilo Escriba Palomino.

El pishtaco, también llamado nakaq o ñakaq, es un degollador que extrae la grasa de sus víctimas, y suele ser un personaje de origen urbano externo a la comunidad. El pishtaco aparece en las películas ayacuchanas Pistha- co (2003) de José Martínez Gamboa, Nakaq (2003) de José Gabriel Huertas, Sin sentimiento (2007) de Jesús Contreras Matías y Jarjacha vs. Pishtaco: la batalla final (2011) de Nilo Escriba Palomino, y en la película huancaína Sangre y tradición (2005) de Nilo Inga Huamán. Una variante del degollador es el personaje del Kharisiri, presentado por el puneño Henry Vallejo en su filme El misterio del Kharisiri (2004). Especie de brujo con capacidad de transformarse en animal, que hace pactos con un espíritu maligno a quien le ofrece sacrificios humanos, el Kharisiri del filme de Vallejo extrae la energía de su hechizada víctima, la periodista Mariela, quien, aunque es rescatada antes de que la sacrifiquen, sufre de un malestar continuo para el que no hay remedio de la ciencia y la va acercando a la muerte. En El misterio del Kharisiri se invierte la amenaza del pishtaco tradicional: no es un ser urbano que roba la grasa de los campesinos, sino un individuo rural que sustrae la energía de una citadina y, a diferencia del pishtaco común, esta criatura es un monstruo interno, no externo a la comunidad.

El monstruo de mayor aparición en las películas fantásticas de terror regionales es el condenado. El cuerpo muerto de ciertos individuos readquiere "el alma que no es admitida en los sitios a los cuales va destinada, por razón de ciertas culpas juzgadas de gravedad excepcional" (Morote Best, 1988, p. 137). En algunos filmes ayacuchanos, el condenado -quien 
suele vestir hábito franciscano- aparece vinculado al jarjacha. En Qarqacha, el demonio del incesto de Mélinton Eusebio, el jarjacha muerto vuelve al mundo como condenado, atacando a vecinos desprevenidos. En La maldición de los jarjachas 2 de Palito Ortega Matute, el jarjacha convierte en condenados a sus víctimas, quienes empiezan a deambular con apariencia de seres vivos para comer los sesos de otros pobladores.

En Supay: el hijo del condenado (2010) de Miler Eusebio, el niño jorobado quien es fruto de una relación incestuosa- es ejecutado por el pueblo de la misma manera en que lo fue su padre; luego, retorna como condenado, matando a sus enemigos y devorando sus vísceras. En la segunda parte del filme La tumba del Supay (2013), padre e hijo condenados se levantan de sus tumbas para cobrar nuevas víctimas. Otro condenado vengador, pero con conocimientos de artes marciales, es el de las películas puneñas Condenado en la pequeña Roma (2007) y El regreso del condenado en el poder andino (2011) de Edwin J. Vilca Yávar, que comprenden —además - escenas evocadoras de ciertos wéstern italianos.

Una variante del condenado es "el condenado por amor": aquel enamorado que jura amar a su prometida más allá de la muerte, y regresa como condenado a buscarla para arrastrarla consigo al más allá. Morote Best lo describe dentro de los relatos de "huida mágica" (Morote Best, 1988, pp.
115-128). Aparece en Condenado de amor (Puno, 2001) de Ramiro Díaz Tupa, y Te juro amor eterno (Junín, 2010) de Luis Gonzales y León Cáceres, con guion de Nina Peñaloza. Este último es un filme híbrido que muta de melodrama rural a película de horror, donde el condenado adquiere rasgos de zombi caníbal. En El Aya Tullu (2010) del ayacuchano Julio Oré Oriundo, encontramos también a un espíritu maligno enamorado, cuyos huesos deformes permanecen insepultos.

La uma (o cabeza voladora de bruja), mencionada ya en la Crónica de Guamán Poma, inspira la película ayacuchana Uma, cabeza de bruja (2005) de Lalo Parra y la puneña La casa embrujada (2007) de Joseph Lora.

Según el antropólogo Tito Castro, las películas de terror regionales representan sociedades donde existe anomia debido a un "terrible conflicto" (Ayacucho) o a una transformación constante, pero sin "supervisión o gerencia por parte de un Estado central" (Puno). Los filmes expresarían la percepción de corrosión moral y falta de legitimidad de las autoridades en esos lugares, así como la necesidad de justicia. Dice Castro que "de algún modo estos filmes reflejan una especie de compensación, pues subliman una serie de insatisfacciones, propias de un desorden social en las regiones, a través de sanciones que vienen sobrenaturalmente, desde otro mundo, lo que genera aquel equilibrio que no existe en la realidad" (Cabrejo, 2010, p. 53). 
En el caso de los filmes ayacuchanos habría, en nuestra opinión, un simbolismo más concreto. Representarían la vivencia del terror experimentado durante el conflicto armado interno de las décadas de 1980 y 1990; un terror que tendría tanto agentes externos (simbolizados por los pishtacos) como internos (los jarjachas), y que se teme que vuelva a emerger (los condenados, aquello que no está aún definitivamente muerto).

\section{Melodrama}

El melodrama surge históricamente como un espectáculo basado en el exceso y dirigido a un público urbano de origen campesino que busca una orientación moral en un mundo en transformación (Martín Barbero, 1991; Brooks, 1995). No es casual que el melodrama sea el género más abordado por los cineastas de Juliaca (región Puno), una de las ciudades peruanas con más alta tasa de crecimiento en las últimas décadas (Bordas, 2009, p. 232); crecimiento que ha originado profundos cambios no solo económicos, sino también sociales, psicológicos y éticos en la población. Juliaca no es, sin embargo, la única ciudad donde se realizan melodramas, los hay también en Ayacucho, Huancayo y Cajamarca.

Un gran tema del melodrama es el de la filiación. Se halla en filmes sobre niños abandonados y perdidos, bastardía, padres desconocidos e hijos pródigos. La representación de la niñez desamparada es frecuente en los filmes regionales. Quizá el mayor éxito comercial del cine altiplánico sea El huerfanito (2004) de Flaviano Quispe. Tuvo un extenso recorrido por provincias, e inclusive estreno comercial en Lima; copias en DVD de la película siguen vendiéndose en los mercadillos piratas de todo el país. La orfandad también se encuentra en otros filmes puneños: Niños pobres (2009) de Julián Miranda y Marcados por el destino (2009) de Óscar Gonzales. La primera película del ayacuchano Palito Ortega Matute, Dios tarda, pero no olvida (1997), puede ser considerada asimismo un melodrama de este tipo; aunque cercano al cine social (el protagonista queda huérfano a causa de que Sendero Luminoso asesina a sus padres), la estructura es claramente melodramática, así como el final consolador: después de sufrir hambre y maltratos, y de vencer a la tentación del delito, el niño es rescatado por un sacerdote que lo lleva al templo.

El motivo de la bastardía y el deseo de reconocimiento se hallan en El hijo del viento (2009) de Flaviano Quispe, donde un niño campesino huye de su casa para buscar a su padre, a quien no conoce. Hijos pródigos encontramos en los filmes juliaqueños Triste realidad (2004) y Lágrimas de madre (2004) de Fredy Larico, que muestran a humildes madres de origen campesino padecer la incorporación de sus hijos a pandillas urbanas. Cuando los hijos se arrepienten, ya es muy tarde. Algo similar ocurre en la exitosa Sufrimiento de madre (2009) del huancaíno Daniel Núñez, donde un hijo contrito llega 
a destiempo al sepelio de su madre, a quien ha causado dolor con su mal comportamiento. Sufrimiento de madre ha tenido una secuela dirigida por el mismo Núñez (El vástago y su promesa. Madre 2, 2010) y varios imitadores. Pero no solo hay madres que padecen, también existen padres sufrientes. En Lágrimas y carcajadas (2007) del chotano Elmer Mejía Tantaleán, un padre hace grandes esfuerzos para criar a sus hijos, quienes no corresponden a su cariño y abnegación. El ayacuchano Marcelino Huamán, por su parte, narra en Mi esperanza (2005) las desventuras de un padre viudo, y en Cántaro, el hijo desobediente (2010) cuenta la historia de un joven rebelde con una escena final muy parecida a la de Sufrimiento de madre, pero en este caso es referida al entierro del padre. Cántaro... ha tenido también considerable acogida del público; se han realizado ya dos secuelas del filme. Tanto Sufrimiento de madre como Cántaro... son melodramas cristianos respaldados por iglesias evangélicas.

Como sabemos, la ciudad en el melodrama es un lugar de perdición, engaño y confusión; pero también de movilidad social. En los melodramas rurales, el personaje citadino (o el nativo del campo que regresa con modos urbanos) puede ser agente del mal o factor de renovación. En ambos casos, pone en riesgo la estabilidad de costumbres y valores. En Amor en las alturas (2008) del juliaqueño Percy Pacco, el héroe y su familia son apartados por un villano envidioso e hipócrita de su pueblo y terminan en la mina
La Rinconada, ámbito infernal. En Casarasiri (2010) del también juliaqueño Joseph Lora, el joven citadino que maneja una moto y viste casaca de cuero es un malvado. En la huancaína Te juro amor eterno (2010), el hijo del hacendado que estudia medicina en la ciudad, y retorna en sus vacaciones al campo, se enamora de la hija de un peón y atenta con ello contra el rígido orden social. Tanto en Casarasiri como en Te juro amor eterno la resolución de la trama es conservadora: en Casarasiri, tras descubrirse la perversidad del villano, se celebra una ceremonia de bodas tradicional entre dos jóvenes oriundos de la comunidad; en Te juro amor eterno, el relato sufre un giro radical y el género cambia de melodrama a fantástico: el joven galán, tras morir trágicamente, se convierte en un condenado por amor (con comportamiento de zombi caníbal) y persigue a su amada, para terminar arrastrado por unos demonios al infierno; la trasgresión social es castigada.

No obstante, también hay melodramas rurales de amores contrariados por causas sociales, donde la narración genera simpatía por la pareja trasgresora; tal es el caso de las películas cajamarquinas El amor de Hupashi (2012) del chotano Adán Díaz Torres y Coraje (2004) de Héctor Marreros. Melodrama juvenil que alerta sobre los peligros de alejarse de la virtud es Trampas de tu lado oscuro (2013) del chiclayano Óscar Liza, sobre una estudiante universitaria que desea tener experiencias intensas y es violada por un profesor que, más tarde, descubre que la chica 
es su hermana. El melodrama de adicción lo hallamos en Vicio maldito (2000) de Germán Guevara, donde el protagonista se vuelve alcohólico, pero al percatarse de que ha estado a punto de provocar la muerte de su esposa, decide rehabilitarse. En Marcados por el destino (2009) del puneño Óscar Gonzales, la lucha es contra la enfermedad mental, y el reconocimiento tiene lugar después de que el protagonista (maltratado de niño y aquejado de esquizofrenia) ocasiona la muerte de su querida hermana. El melodrama bélico se manifiesta en La promesa (2013) del huancaíno Juan Carlos Ambrosio, ambientado en la guerra del Cenepa: un joven jura a la madre de su mejor amigo que protegerá a este aun a costa de su propia vida, como en efecto sucede; la escena final muestra el feliz reencuentro de madre e hijo gracias al sacrificio del héroe. El énfasis estilístico y actoral, la estructura con caída, sufrimiento, reconocimiento y final consolador que afirma valores establecidos, permiten calificar a todos estos filmes como melodramas.

\section{Realismo social}

Aunque la mayoría de los melodramas citados tienen un evidente contenido social, hay películas que se alejan de las convenciones de este género y ponen mayor énfasis en la descripción o denuncia de problemas sufridos por individuos de una comunidad en determinadas circunstancias históricas.

Consideraremos filmes de realismo social tanto a los que Raymond
Durgnat (1975) ubica específicamente dentro de este género como a los que llama populistas. Es decir, a aquellos que pretenden presentar "objetivamente" casos desde una distancia formal y narrativa cercana al documental expositivo, así como a los protagonizados por personajes de sectores populares con un cierto grado de estilización, pero sin llegar a ser melodramas.

La película que da inicio al movimiento de cine regional, Lágrimas de fuego (1996), es un filme sobre las pandillas juveniles ayacuchanas que surgieron inmediatamente después de que terminara el conflicto armado interno. Si bien hay muchos elementos melodramáticos en el filme (el protagonista sufre la muerte de su madre a causa de sus acciones violentas, motivo que retomaría Fredy Larico en Triste realidad), existen en la película recursos de distanciamiento que la alejan del melodrama. En una de sus mejores escenas, los personajes cuentan sus vidas, uno a uno, durante una reunión, lo que recuerda de cierto modo un pasaje similar en Gregorio (1985) del grupo Chasqui. Asimismo, el filme contiene imágenes documentales de una marcha de protesta en Ayacucho contra el pandillaje, cifras estadísticas sobre delincuencia juvenil en la ciudad y un personaje -que aparece en el prólogo y en el epílogo- que da al relato un carácter de "estudio de caso", a la manera del naturalismo literario.

La fuerza de un héroe (1997) de Ramiro Díaz Tupa muestra a un oficial que 
crea las rondas urbanas y el Comité de Autodefensa de Juliaca, a fin de enfrentar el terrorismo y la delincuencia común. Se basa en un personaje real. También en El pecado (2006) de Palito Ortega Matute, se echa mano de un individuo de la vida real; el director cuenta la historia ficcionada de Mario Eduardo Córdova ("Yahaira"), conocido travesti ayacuchano que practica la prostitución y actúa en la película representándose a sí mismo.

Entre los filmes sobre el conflicto armado interno destaca nítidamente $E l$ rincón de los inocentes de Palito Ortega Matute, grabado en 2005 y estrenado en Ayacucho en 2013, luego de haber ganado un premio de posproducción del Ministerio de Cultura. Una mujer sufre el asesinato de su hijo mayor y la desaparición de su marido a manos de las fuerzas del orden, clama por justicia al lado de su hijo pequeño, pero también ella es asesinada por los militares. Años después, el hijo sobreviviente - ya joven - acude a una sesión de la Comisión de la Verdad y adopta una posición crítica frente a sus miembros. La primera hora del filme es sumamente intensa. En el año 2000, Palito Ortega Matute había realizado ya otra película sobre el tema: Sangre inocente, sobre ayacuchanos acusados injustamente de terrorismo que son perseguidos y torturados por las Fuerzas Armadas. Tiene casi terminada $\mathrm{La}$ casa rosada, en torno a un centro de tortura que funcionó durante la década de 1980 en Ayacucho.
En 1999, Luis Berrocal realizó Mártires del periodismo, donde un periodista español, en su afán de investigar la matanza de Uchuraccay, se interna en un infierno bélico del que no logra salir. En 2003, después de varios años de grabación, Berrocal exhibió Gritos de libertad, en base a testimonios de los ronderos de las comunidades del valle de La Compañía, que lucharon contra Sendero Luminoso. En Secuelas del terror (2010), Juan Camborda presenta a un exmilitar que sufre alteraciones mentales como consecuencia del conflicto armado interno en el que participó.

En otras películas se sugiere una reflexión sobre la importancia de la tradición, como en las huancaínas Identidad (2007) de Dalmer Quintana y Con nervios de toro (2012) de Nilo Inga Huamán; y, en cierta medida, en la juliaqueña El abigeo de Flaviano Quispe, en torno al conflicto entre un ladrón y la comunidad que lo castiga. Pero también se censuran costumbres arcaicas como los matrimonios arreglados por los padres en la sorprendente Rosa (2010) de Dalmer Quintana, un filme que representa con crudeza y humor la vida de una adolescente en el campo.

Chicama del trujillano Omar Forero, cinta ganadora de cinco premios en el Festival de Lima del año 2012, cuenta la historia de un profesor de primaria enviado a una zona rural. No obstante, el estilo minimalista empleado en el relato asemeja esta película a las otras realizadas por Forero, y la acerca al filme de autor. 


\section{Documental}

La producción de documentales en las regiones es menos notoria que la de ficción. La mayoría de los documentales son de mediano o cortometraje, y no tienen como destino su exhibición pública a cambio del precio de una entrada. Algunos realizadores de ficción hacen trabajos por encargo para instituciones, y no los suelen mencionar dentro de su filmografía. No obstante, existen regiones donde se observa mayor interés en el documental y variedad de propuestas en este género, como en Arequipa, Lambayeque, Loreto y Cusco.

Algunos documentales destacados en Arequipa son Cable a tierra (2013), filme autobiográfico o "performativo" de Karina Cáceres; los cortometrajes sociales y de autor del colectivo Monopelao, y los mediometrajes expositivos del grupo El Videógrafo. En Lambayeque, sobresalen los largometrajes Vivir (2010) y Proyección 19 (2013), compuestos por episodios realizados por alumnos de la Universidad Católica Santo Toribio de Mogrovejo, el mediometraje Yuraktukto de Gisella Burga, sobre el trabajo de una enfermera en una comunidad de altura, y el corto Viajero (2012) de Manuel Eyzaguirre, un descarnado y sentido testimonio que el director recoge de su propio padre, chofer interprovincial y enfermo de cáncer. En Loreto, se distinguen los cortometrajes de contenido social y poético de la asociación La Restinga, y los cortometrajes del pintor Christian
Bendayán: Tengo un primo que es pintor (2005), Los tigres del pincel (2007) y Altar (2008). En Cusco, destacan los "videoramas" (documentales en imágenes fijas) del antropólogo cusqueño César A. Vivanco; Inkarri: 500 años de resistencia del espíritu inca en el Perú (2013), largometraje sobre la comunidad Q'eros de José Huamán Turpo, y los cortometrajes de Ángel Romero Pacheco y Alfredo Velarde.

En otras regiones, la actividad documental es menor, pero se han realizado algunos filmes apreciables. En Cajamarca, los documentales producidos por Rosa Isabel Guarniz: La magia del succha; Alegría, la fiesta de Cajamarca; y En el corazón de Conga. En Ayacucho, Apuyaya (2012) de Juan Camborda, sobre la Semana Santa en Ayacucho. En Junín, La danza del zorzal (2013) de Omar Sapaico, largometraje acerca del huaylarsh. En Puno, Hananpacha de los hermanos Carlos y José Vallejo, que aborda la cultura del Altiplano (danzas y costumbres), y el corto Puqllasunchis (2006) de Henry Vallejo, que tiene como motivo un parque de diversiones.

\section{Experimental y animación}

En Cusco encontramos cultores de un tipo de videoarte que difícilmente se distingue del cine experimental. Entre ellos se puede mencionar a Alfredo Velarde, Jorge Flores Nájar, Brady Romero Ricalde y Fredy Romero Peralta. La mayoría mezcla tradición y modernidad e invita a reflexionar sobre la identidad nacional. 
Existen, también, trabajos de animación narrativa y educativa. Destaca el cusqueño Fernando Tagle Carbajal, autor -entre otros cortos muy apreciables- de El cóndor y el zorro. Un reto de altura (2011), recreación de una leyenda andina, y El balcón de un yanakuna (2008), que narra la historia de la captura y decapitación de Túpac Amaru I y su encuentro con el virrey Toledo, elaborado sobre la base de dibujos de Guamán Poma.

La arequipeña Cecilia Cerdeña ha dirigido numerosos cortometrajes que constituyen experimentos narrativos y no narrativos; en varios incluye animación. No carecen de humor e ingenio. Reviste interés, asimismo, Chamán, cortometraje de animación stop motion con plastilina sobre un hombre que trata de escapar de una casa, realizado por el arequipeño Mauricio Banda.

\section{Modo narrativo y dramaturgia}

La mayoría de los filmes de ficción adoptan estructuras de género. El modo narrativo es el clásico, inspirado en el drama aristotélico.

La influencia del cine de género norteamericano que los realizadores han consumido es evidente en los filmes de horror, así como la del cine de género hindú y mexicano en el caso de los melodramas. Ahora bien, entre el relato de género (cercano a la tradición oral), que da prioridad a la acumulación de sucesos emocionantes, y el modo narrativo clásico, que enfatiza la causalidad, existe siempre tensión, incluso en las producciones de Hollywood (Altman, 2011). Esta es aún mayor en numerosas películas regionales en las que existe una muy débil causalidad. Esta debilidad se extiende hasta el montaje, donde las fallas de raccord son constantes, sobre todo los saltos de eje.

Muchos cineastas regionales (la mayoría de los que hemos entrevistado) son conscientes de la escasa causalidad en sus relatos, y lo asumen como una falla que deben corregir para poder competir con producciones limeñas y extranjeras. Consideran que deben manejar mejor las convenciones del modo narrativo que tácita o explícitamente han elegido, y expresan su deseo de llevar talleres de guion. Sin embargo, habría aquí un conflicto entre un modo narrativo, cuyas convenciones los cineastas aspiran a controlar para poder entrar competitivamente en el mercado, y las matrices culturales que los conducen a narrar de determinada manera (no causal).

De otro lado, los espectadores de origen popular que consumen estos filmes (que son la mayoría) no parece que tuvieran dificultades en seguir el relato, pese a la falta de causalidad, pues compartirían las mismas convenciones narrativas enraizadas en la oralidad. Quienes sí rechazan los filmes por ese motivo (aunque también, en ocasiones, a priori, simplemente por tratarse de relatos de género) son -en las mismas regiones- jóvenes espectadores urbanos citadinos de 
clase media o alta, e inclusive algunos cineastas dedicados al documental de autor o al cine experimental.

Por cierto, también hay un número menor de cineastas regionales (la mayoría con formación académica) que optan claramente por modos narrativos distintos del clásico. El caso más notorio es el del trujillano Omar Forero.

\section{Lenguaje audiovisual}

La mayoría de los largometrajistas no lucen un manejo fluido del lenguaje cinematográfico (o modo de representación institucional, para emplear la categoría propuesta por Noël Burch, en este caso quizá más exacta). Sin embargo, declaran aspirar a ello.

El antropólogo Raúl Castro habla de una "estética de la distorsión" respecto al modo de representación de las películas regionales. Ante la pregunta del crítico José Carlos Cabrejo de si aquella estética tiene que ser una marca constante de ese cine, teniendo en cuenta que "muchos de estos directores manifiestan que quieren limpiar, mejorar, depurar el acabado de sus películas", Castro responde que "ya es un recurso, un modo, una forma de acercarse a contar algo cinematográficamente". Añade:

Si bien estos videastas con seguridad van a esforzarse en mejorar sus propuestas, van a seguir apegados a esta estética, porque de eso se han nutrido mucho tiempo (Cabrejo, 2010, p. 54).
El ecuatoriano Christian León destaca, por su parte, que las películas ecuatorianas de lo que él llama "Ecuador bajo tierra" (y que son semejantes a las películas regionales peruanas) constituyen palimpsestos donde confluyen diversos tiempos, narrativas y géneros, y que esta "incesante capacidad para la asimilación y la mezcla es el preludio para el desordenamiento de los códigos del lenguaje y la narración" (Alvear \& León, 2009, p. 22).

No obstante estas apreciaciones, más que al desordenamiento de los códigos, o a la creación de un nuevo modo de representación o un nuevo lenguaje, un conjunto importante de cineastas regionales peruanos (la mayoría de los entrevistados por nosotros) parece tender pragmáticamente hacia el aprendizaje de los códigos para ampliar su mercado, poder competir con producciones limeñas y extranjeras, y afirmarse como cineastas profesionales.

En las producciones regionales, en general, se nota una mayor asimilación de las convenciones hegemónicas de representación visual y sonora que de las convenciones dramatúrgicas clásicas y de montaje. El empleo de planos, ángulos, movimientos de cámara, composición, ruidos y música, e inclusive de lo profílmico, suele acercarse bastante a lo convencional; $y$ el aprendizaje del modo de representación institucional es notorio de una producción a la siguiente.

Un problema muy evidente de puesta en escena en la mayoría de las 
películas de ficción (y ampliamente reconocido como tal por los propios directores) es la actuación, pese a que varios realizadores tienen formación teatral. La causa sería la escasez de escuelas de actuación fuera de Lima. Como ya se ha señalado, generalmente, los actores son empíricos, no profesionales, elegidos en un casting y con solo un precario taller de preparación. Aun así, debe destacarse la presencia de algunos actores y actrices empíricos de talento.

\section{Técnica}

La búsqueda de una mejor calidad de imagen y sonido es constante en la mayoría de los cineastas, sobre todo entre quienes dicen que desean alcanzar estándares que les permitan competir con filmes limeños y extranjeros en un futuro próximo. Algunos de ellos comenzaron a grabar en formato VHS o S-VHS en la década de 1990, pasaron a usar luego las cámaras de 3/4, miniDV, handycam digitales, y actualmente emplean las cámaras fotográficas DSRL, que permiten cambio de lentes y registro en full HD. Hace poco tiempo, la empresa del arequipeño Miguel Barreda ha adquirido una Black Magic.

Como consecuencia de la adquisición de equipos más sofisticados, ha mejorado la calidad de la fotografía. No obstante, los cineastas reconocen que les faltan conocimientos de fotografía cinematográfica, inclusive aquellos que son buenos fotógrafos $y$ se ganan la vida en ese oficio. La necesidad de capacitación es mayor aún en sonido; prácticamente, no existen especialistas en sonido (una excepción es el músico y realizador cusqueño Ángel Romero, quien es sonidista autodidacta). La edición, en la mayoría de los casos, sigue haciéndose en PC con Adobe Premier Pro o programas bajados gratuitamente de internet. Las copias en DCP (formato necesario para la exhibición comercial en salas de estreno con sistema digital) son escasas, como lo ha sido la exhibición en multisalas; en algunas ocasiones, se han producido copias en DCP a un costo menor que el promedio, gracias a las habilidades de los mismos cineastas en el manejo de cierto software.

Algunos realizadores han construido sus propias herramientas de rodaje, como los hermanos Vallejo (Puno), autores de grúas y mecanismos para filmaciones subacuáticas que luego han alquilado o prestado a colegas.

\section{Apoyo institucional}

\section{Gobiernos regionales y municipales}

Prácticamente todos los cineastas entrevistados lamentaron no contar con el apoyo de los gobiernos municipales y regionales para la producción de sus películas. Inclusive se quejaron de que los administradores de algunos locales municipales a los que acudían para exhibir sus filmes les cobraban altas tarifas de alquiler. 
En general, los cineastas consideran que los gobiernos municipales y regionales rechazan invertir en el cine regional, porque no consideran al cine como actividad o industria cultural, sino como negocio del espectáculo. Sin embargo, algunos realizadores admiten deficiencias propias en la oportunidad de solicitar apoyo a los gobiernos, pues lo hacen muchas veces cuando el presupuesto anual de los mismos ya ha sido aprobado.

Los cineastas reconocen, en cambio, la colaboración de instituciones como la policía y la Iglesia católica.

\section{Conacine, Dicine, DAFO}

El apoyo del Estado se ha limitado en estos años, prácticamente, a la convocatoria de concursos y la elaboración de efímeros talleres. No ha podido incluir al llamado cine regional dentro de una política cultural coherente, porque sencillamente esta no existe.

El Consejo Nacional de Cinematografía (Conacine) fue creado por la Ley N. ${ }^{\circ} 26370$ de 1994. Entre sus principales facultades se hallaba la convocatoria de concursos nacionales anuales de corto y largometraje. En 2006, Conacine dio inicio a la convocatoria de Concursos de Proyectos Exclusivos para las Regiones (excepto Lima Metropolitana y Callao). Esta convocatoria parte de la consideración de que los cineastas regionales se hallan en desventaja con relación a los cineastas limeños cuando tienen que competir con ellos en los concursos nacionales, debido al menor presupuesto que manejan, las menores posibilidades de información y formación que tienen, y el menor nivel técnico alcanzado. En virtud de ello, se aplica el criterio de la "discriminación positiva", excluyendo de la convocatoria de participación a Lima Metropolitana y el Callao. Los cineastas regionales, por el contrario, pueden participar tanto en los concursos para las regiones como en los nacionales. Conacine llamó a estos concursos y entregó los premios respectivos en 2006, 2007, 2009, 2010 у 2011. En el año 2010 se decretó la "fusión por absorción" de Conacine por parte del recientemente creado Ministerio de Cultura, que no se hizo efectiva sino hasta 2011, lo que trajo consigo la disolución de Conacine. Los concursos fueron convocados en adelante por la Dirección de Industrias Culturales (Dicine) en 2012, y por la Dirección del Audiovisual, la Fonografía y los Nuevos Medios (DAFO) en 2013.

De trece proyectos ganadores de los premios del Estado, solo ha sido estrenada en el circuito comercial de los multicines la película trujillana Chicama de Omar Forero. La huancavelicana Don Melcho, amigo o enemigo (premiada en 2007), de Arnaldo Soriano, y la huancaína Con nervios de toro (premiada en 2009), de Nilo Inga, han sido exhibidas únicamente en salas de circuito cultural.

En 2012, se realizaron los primeros concursos convocados por Dicine, luego de la desaparición de Conacine. Dicine aumentó el monto destinado 
al Concurso de Proyectos de Largometraje de Ficción Exclusivo para las Regiones, incorporó premios para la categoría "regional" en otros concursos, e invitó a especialistas extranjeros para que formaran parte de los jurados al lado de los nacionales, en busca de lograr una mayor objetividad en los fallos. Los resultados no fueron los esperados. El jurado del Concurso de Proyectos de Largometraje Documental consideró desiertos los premios en la categoría "regional". El jurado de cortometrajes premió a veinticinco cortos, de ellos, apenas a cinco cortos regionales. El premio a largometraje regional independiente o experimental también se declaró desierto. En 2013, ya bajo la Dirección del Audiovisual, la Fonografía y los Nuevos Medios (DAFO), continuaron declarándose desiertos algunos premios en la categoría regional, en los concursos de Obras Cinematográficas Experimentales y Proyectos de Gestión Cultural para el Cine y el Audiovisual. Los jurados han justificado sus decisiones invocando deficiencias en los proyectos.

Los premios desiertos no son el único indicador de que algo anda mal en el apoyo por parte del Estado al cine regional. En comparación con la cantidad de películas que se producen en las regiones, son pocos los proyectos presentados en los concursos. La abstención de la mayoría de los cineastas regionales tendría varias causas. Muchos de los cineastas entrevistados por nosotros han expresado su desconfianza respecto de los concursos, pues temen que estos se encuentren amañados. Otros han destacado lo trabajoso y oneroso que les resultaría la formalización de su empresa, con el objetivo incierto de ganar un concurso; prefieren invertir el tiempo y el dinero que emplearían para ello en la producción de una película que les permita obtener réditos más seguros en su región. También hay quienes demandan una mayor información y capacitación en la elaboración de proyectos; no les parece suficiente ni del todo accesible la información colgada en internet por el Estado. Debe tenerse en cuenta, como hemos señalado al referirnos a los géneros en el cine regional, que en la producción de las regiones andinas predomina una narrativa con fuerte matriz de oralidad. La mayoría de los cineastas regionales andinos tiene dificultad para expresarse por escrito (lo evidencian los créditos mismos de sus filmes que contienen errores ortográficos y de sintaxis, entre otros); sin embargo, el Estado impone como requisito para presentarse a los concursos una elaboración de proyectos que supone un manejo fluido de la escritura y de las formalidades burocráticas. Por consiguiente, quienes se hallan en ventaja son aquellos cineastas que mayor contacto tienen con la cultura letrada.

De otro lado, el Estado no ha definido aún con claridad quién es un cineasta regional, lo que ha motivado que directores que no residen en las regiones se presenten a los concursos. Si bien los concursos están abiertos no para individuos, sino para empre- 
sas, asociaciones y centros educativos, queda abierta la posibilidad de que se cree una empresa o asociación en una región solamente para acceder a la convocatoria, sin que ello implique una actividad continua en la región ni que los realizadores vivan allí, lo que distorsionaría el objetivo de los concursos. Para evitar que esto suceda podría quizá precisarse en las bases de los concursos que el director acredite residencia en la región por un número determinado de años.

En las entrevistas realizadas, varios cineastas han demandado no solo talleres de elaboración de proyectos, sino cursos de duración prolongada sobre escritura de guiones y aspectos técnicos. Estas demandas coinciden con recomendaciones de algunos jurados, contenidas en actas de los concursos. Si bien Conacine organizó contados talleres, las opiniones de los cineastas que asistieron a ellos no son del todo favorables. Unos reconocen que fueron positivos, pues les permitieron conocer a sus colegas y compartir inquietudes; otros señalan que, en lugar de motivarlos, los talleres los desanimaron, pues quienes los impartían no tomaban en cuenta los escasos recursos económicos con los que contaban los cineastas regionales, y hacían aparecer al cine como excesivamente caro y lejano de sus posibilidades reales. Quienes sí encontraron la información recibida en los talleres como positiva lamentaron que fueran de duración tan corta. Lo adecuado sería, probablemente, la organización de talleres de larga duración (incluso de meses) desarrollados en las mismas regiones. En el caso de los talleres de elaboración de proyectos, se requeriría un monitoreo permanente a cargo de asesores, a fin de que los proyectos pudieran presentarse a los concursos con posibilidades de premiación. Sin embargo, se ha expresado, también, una autocrítica de parte de los cineastas regionales respecto de su actitud ante los talleres de elaboración de proyectos que reclaman. El cineasta Nilo Inga relata que cuando el productor y director Julio Vizcarra fue a Huancayo a dictar un taller en nombre de Conacine, la asistencia de los realizadores locales fue muy nutrida al inicio, pero después de que sacaron fotocopias a los modelos de proyectos que Vizcarra había llevado, la mayoría de ellos no regresó al taller.

El trujillano Omar Forero ha llamado la atención sobre la superficialidad que supone dictar talleres solamente de elaboración de proyectos, cuando lo que se requiere es tener claridad sobre las razones por las que se desea hacer cine, el tipo de cine al que se aspira y el público al que se quiere llegar. Forero considera que más importante que aprender a elaborar un proyecto es la creación de escuelas de cine en las regiones. Agregaríamos que aún más importante es una política cultural por parte del Estado orientada hacia el cine nacional que, como repetimos, no existe.

Así como el Estado no ha vinculado el desarrollo del cine regional con la 
educación en cine, tampoco lo ha hecho con la distribución y exhibición de películas regionales. El Estado podría contribuir al desarrollo del cine en las regiones, facilitando el alquiler y uso de locales públicos para los cineastas que desean exhibir sus películas. Como ya hemos señalado, los cineastas se quejan por los altos costos de alquiler de salas municipales y regionales. El Estado podría también respaldar el estreno de películas regionales (de corto o largometraje) en salas de estreno, mediante el régimen de excepción vigente que contempla la Ley N. ${ }^{\circ} 26370$, y convocar a premios de posproducción y distribución exclusivos para regiones, con montos que permitan la elaboración de copias en DCP. Podría, asimismo, promover la transmisión por TV Perú de películas regionales, con una publicidad adecuada y pagando los derechos correspondientes a los cineastas por estas emisiones. En un mediano plazo, podría contemplar la construcción de salas alternativas en las regiones, donde se exhiban películas que no tengan un fácil acceso al circuito comercial, y aprobar una nueva ley de cine donde se considere una cuota de pantalla para que en los multicines comerciales de las regiones se puedan exhibir las películas que allí se producen.

\section{El problema del nombre}

En el presente artículo hemos llamado cine regional al realizado por cineas- tas peruanos que viven y laboran fuera de Lima Metropolitana y el Callao. Un cine que, además, tiene características específicas de producción, realización, distribución y exhibición que hemos descrito en estas páginas. No obstante, el término es discutido por los mismos cineastas. Varios de ellos lo encuentran despectivo, al igual que la denominación cine provinciano. Prefieren que se hable simplemente de cine peruano; sin embargo, al llamarlo cine peruano se corre el riesgo de invisibilizarlo. Durante años se ha identificado al cine peruano con el cine hecho en Lima. Algunos de los mismos directores entrevistados, al ser preguntados sobre qué películas peruanas recordaban, respondieron citando filmes limeños, y solo al pedirles que citaran películas regionales mencionaron las que no fueron producidas en la capital. El director arequipeño Miguel Barreda ha hecho una sugerencia interesante sobre el particular: que se hable de cine peruano arequipeño, cine peruano ayacuchano, cine peruano puneño, etcétera; es decir, de cine peruano como producto, con una denominación de origen. En cualquier caso, desde hace dieciocho años estamos ante un nuevo cine peruano que representa escenarios, prácticas culturales, vivencias y sensibilidades antes ausentes en las pantallas del país. Un cine, cuyo desarrollo en el futuro depende no solo del talento y tesón de sus realizadores, sino, en gran medida, del apoyo institucional que se le brinde. 


\section{Referencias}

Altman, R. (2011). Los géneros de Hollywood. En: G. P. Brunetta. (Ed.), Historia mundial del cine, volumen 1 , tomo 1 (609-622). Madrid: Akal

Alvear, M. \& León, C. (2009). Ecuador bajo tierra. Videografías en circulación paralela. Quito: Ochoymedio.

Bordas, C. (2009). "Mientras Puno danza, Juliaca avanza...": el proceso de urbanización en las orillas del lago Titicaca (departamento de Puno, Perú). En J. M. Cáceres-Olazo Monroy (Ed.), Cultura, historia y sociedad en la meseta del Q'ollao. Lima: Universidad Nacional Federico Villarreal, Facultad de Humanidades, Departamento Académico de Historia, Antropología y Arqueología; Colegio Profesional de Antropólogos, Consejo Departamental Descentralizado Lima.

Brooks, P. (1995). The Melodramatic Imagination. Balzac, Henry James, Melo- drama, and the Mode of Excess. New Haven, CT: Yale University Press.

Burch, N. (1995). El tragaluz del infinito. (Contribución a la genealogía del lenguaje cinematográfico). Madrid: Cátedra.

Cabrejo, J. C. (2010). La justicia del más allá. El cine de terror regional. Entrevista con Raúl Castro. Ventana indiscreta, 3, 52-55. Lima: Universidad de Lima.

Durgnat, R. (2012). Género: populismo y realismo social. En M. Yáñez Murillo (Ed.), La mirada americana. Cincuenta años de Film Comment. Madrid: Festival Internacional de Cine Las Palmas de Gran Canaria, T\&B.

Martín Barbero, J. (1991). De los medios a las mediaciones. Barcelona: Gustavo Gili.

Morote Best, E. (1988). Aldeas sumergidas: cultura popular y sociedad en los Andes. Cusco: Centro de Estudios Rurales Andinos Bartolomé de Las Casas. 


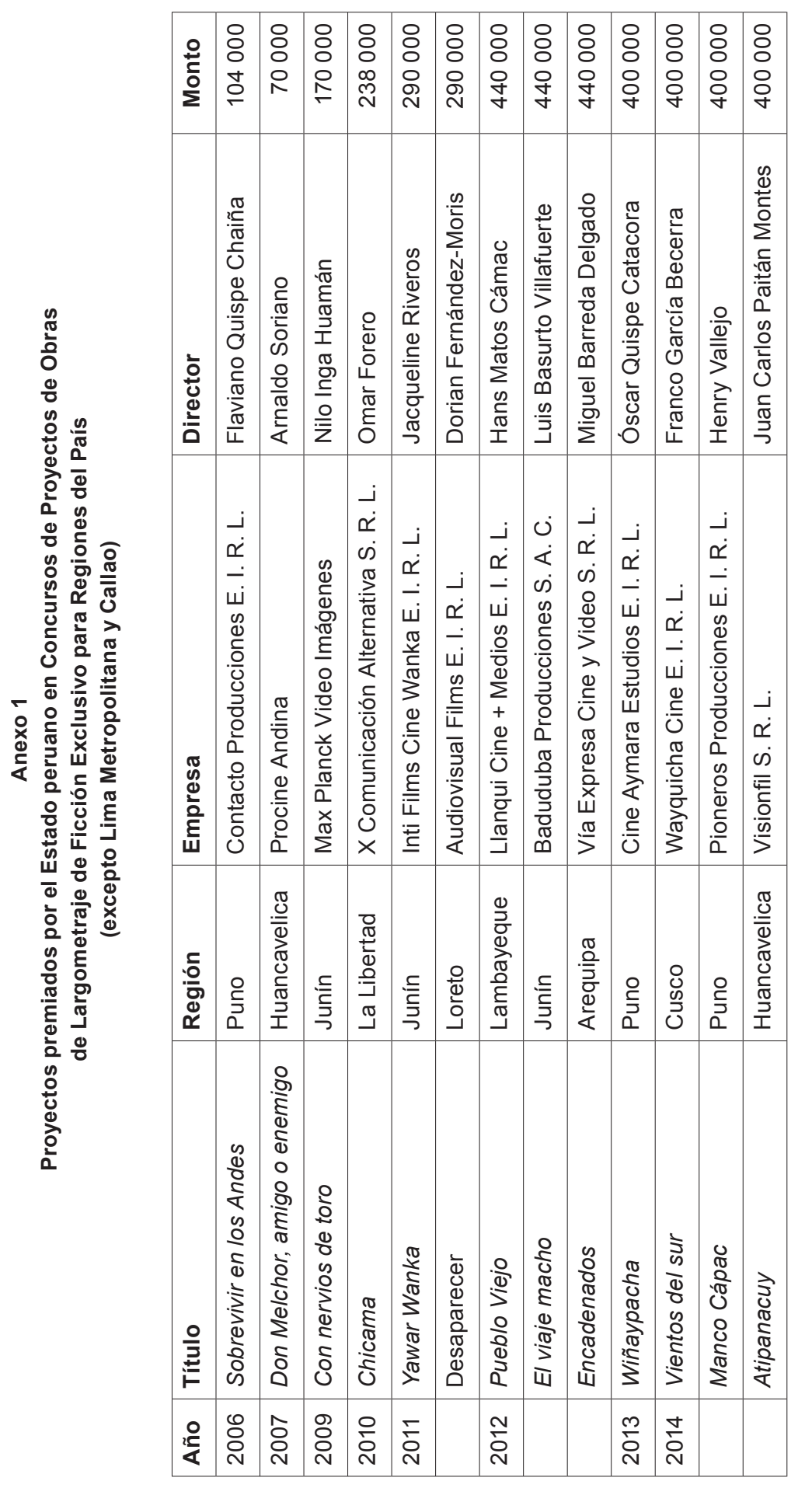

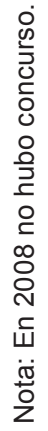


Anexo 2

Directores entrevistados

Apurímac: Víctor Zarabia (El último guerrero Chanka)

Arequipa: Roger Acosta (Mónica: más allá de la muerte), Mauricio Banda (Chamán), Miguel Barreda (Ana de los Ángeles), Karina Cáceres (Cable a tierra), Cecilia Cerdeña (Metanoia), Edward de Ybarra (colectivo Monopelao), Medardo Medina (El degolladito), Jorge Núñez (documentales de El Videógrafo), Juan Manuel Ojeda (Eitianen: el mensajero de la luz), Wildo Ontiveros (Condenadas), Andrea Quevedo ( $E I$ averno), Arnulfo Vargas (documentales de El Videógrafo).

Ayacucho: David Acosta Gutiérrez (Marimacha: La Encarnación), Luis Aguilar (Chullpicha Pipilín), Luis Enrique Berrocal Godoy (Gritos de libertad), Walter Bustamante (Al encuentro del Nazareno), Juan Camborda (Apuyaya), Jesús Contreras (Sin sentimiento), Miler Eusebio (Supay, el hijo del condenado), Mélinton Eusebio (Qarqacha: el demonio del incesto), Jorge Gaitán (Marimacha: La Encarnación), Germán Guevara (Helme), Javier Laguado (Canción de la muerte), Silvio La Rosa (Canción de la muerte), Suriel Navarro Pirca (Condenado: El precio del pecado), Julio Oré (Marimacha: La Encarnación), Palito Ortega (Dios tarda, pero no olvida), Lalo Parra Bello (Uma, cabeza de bruja), Piero Parra Solar (Residuos), Ramiro Velapatiño (Waqra, corazón contento).

Cajamarca: Adán Díaz Torres (El amor de Hupashi), Luz Isabel Guarniz Alcántara (En el corazón de Conga), Héctor Marreros (Coraje), Elmer J. Mejía Tantaleán (Lágrimas y carcajadas), Dante Rubio (La Cuda, La otra cara de la muerte), Lenin Salinas (Encuentro pendiente).

Cusco: Marco Antonio Canales (Huellas de una misión), Maxwell García (Qoyllurit'i, Señor de la nieve resplandeciente), Urpi García (Víctimas de la pantalla), José Huamán Turpo (Inkarri, 500 años de resistencia del espíritu inca en el Perú), Marco Antonio Moscoso (cor- tos experimentales), Ángel Romero Pacheco (Los barrios tradicionales del Cusco y su gente), Fredy Romero (3 Actos), Fernando Tagle (El cóndor y el zorro), Edward Valenzuela (documentales turísticos), César Alberto Venero (Escúchennos cuando todo acabe), César A. Vivanco (documentales en videoramas).

Junín: Juan Carlos Ambrosio (La promesa), León Cáceres (Te juro amor eterno), Christian Cárdenas (Inocente amor), José Miguel García (Wambla light), Luis Gonzales (Te juro amor eterno), Nilo Inga Huamán (Sangre y tradición), Ángel Gabriel Lagos Luján (Voces póstumas de sangre), Daniel Núñez (Sufrimiento de madre), Dalmer Quintana (Rosa), Jacqueline Riveros Matos (Yawar Wanka), Omar Sapaico (La danza del zorzal), Álex Williams Tomás Villa (Madre).

La Libertad: Omar Forero (Chicama).

Lambayeque: Bryan Aguirre (Mosca muerta), Gisella Burga Polo (Yuraktukto), Mauricio Burstein Balmaceda (Dispárame, dispárame), Dalia Carranza (Corto amor), Manuel Eyzaguirre (Viajero), Óscar Liza (Trampas de tu lado oscuro).

Loreto: Dorian Fernández-Moris (Cementerio general).

Puno: Ramiro Díaz Tupa (La fuerza de un héroe), Óscar Gonzales (Marcados por el destino), Joseph Lora (Casarasiri), Percy Pacco (Amor en las alturas), Javier Peralta (El encanto de la sirena), Flaviano Quispe (El huerfanito), Óscar Quispe Catacora (EI sendero del chulo), Francisco Torres (La leyenda del condenado), Carlos Vallejo (Hananpacha), Henry Vallejo (El misterio del Kharisiri), José Vallejo (Hananpacha), Jasmani Vilca (Vientos de amor y pecado).

Tacna: Carlos Vera Munárriz (Verdad o castigo).

Total de directores entrevistados: 81 . 